\title{
KONTRIBUSI KOMPETENSI DAN PERSEPSI TENTANG SUPERVISI PEMBELAJARAN TERHADAP PRODUKTIVITAS KERJA GURU
}

\author{
Hamdani $^{* 1}$, Krismadinata ${ }^{1}$ \\ ${ }^{1}$ Jurusan Teknik Elektro, Fakultas Teknik, Universitas Negeri Padang \\ *Hamdani@ft.unp.ac.id
}

\begin{abstract}
Abstrak- Berhasil tidaknya sekolah mempersiapkan generasi yang akan datang tergantung pada proses pembelajaran yang terjadi di sekolah. Agar fungsi ini tercapai, diperlukan pembelajaran yang mendukung serta guru yang produktif. Penelitian ini bertujuan untuk menganalisi kontribusi kompetensi dan persepsi tentang supervisi pembelajaran terhadap produktivitas kerja guru SMKN 1 Padang. Jenis penelitian ini adalah penelitian korelasional yang bersifat ex post facto. Hasil penelitian menunjukkan terdapat kontribusi yang signifikan antara kompetensi dan persepsi tentang supervisi pembelajaran terhadap produktivitas kerja guru. Berdasarkan temuan penelitian ini disimpulkan bahwa kedua variabel bebas yaitu kompetensi dan persepsi tentang supervisi pembelajaran memegang peranan penting dalam meningkatkan produktivitas kerja guru.
\end{abstract}

Kata kunci： Kontribusi, kompetensi, supervisi, produktivitas kerja

Abstract- The success or failure of schools to prepare future generations depends on the learning process that occurs in schools. In order for this function to be achieved, supportive learning and productive teachers are required. This study aims to analyze the contribution of competence and perception about the supervision of learning on teacher works of productivity SMKN 1 Padang. This type of research is correlational research that is ex post facto. The results showed that there was a significant contribution between competence and perception about the supervision of learning on teacher work productivity. Based on the findings of this study concluded that the two independent variables namely competence and perception of supervision of learning plays an important role in improving teacher productivity.

Keywords: Contribution, competence, supervision, work productivity

\section{Copyright $\odot 2017$ INVOTEK. All rights reserved}

\section{Pendahuluan}

Keberadaan Sekolah Menengah Kejuruan (SMK) merupakan wahana pengetahuan dan keterampilan di sekolah terhadap dunia kerja secara nyata. Hal ini disebabkan karena sekolah merupakan lembaga formal yang diserahi tanggung jawab oleh pemerintah dan masyarakat untuk membentuk generasi manusia yang berilmu pengetahuan. Berhasil tidaknya sekolah mempersiapkan generasi yang akan datang tergantung pada proses pembelajaran yang terjadi di sekolah. Agar fungsi ini tercapai, diperlukan sarana prasarana yang memadai, proses pembelajaran yang mendukung serta guru yang produktif. Pribadi yang produktif akan lebih kreatif dalam berhubungan dengan dunia sekitarnya dengan menciptakan suatu hasil karya melalui kemampuan dan menggunakan pikiran serta perasaannya.
Guru yang produktif adalah kriteria guru yang paling diharapkan untuk dapat mewujudkan tujuan pendidikan [4]. Untuk memberhasilkan guru secara optimal, maka kepala sekolah harus memperhatikan masalah produktivitas kerja. produktivitas kerja guru harus menjadi perhatian kepala sekolah sebagai pimpinan organisasi karena tinggi rendahnya produktivitas kerja guru dapat berpengaruh terhadap pencapaian tujuan organisasi sekolah secara keseluruhan [7].

Permasalahan yang terjadi diantaranya beberapa guru kurang disiplin kerja dalam melaksanakan tugas belum sepenuhnya dilakukan dengan baik. Masih terdapat guru yang datang mengajarnya terlambat dan malas mengajar. Meskipun hanya sebagian kecil saja, tetapi hal ini tentu akan mempengaruhi dan mengganggu proses pembelajaran di sekolah. Dalam menjalankan profesinya masih terdapat permasalahan yang berkaitan dengan kompetensi diantaranya pada 
saat pembelajaran berlangsung, siswa dalam kondisi tidak tenang bahkan meribut dalam kelas saat guru menjelaskan pembelajaran. Ada beberapa guru kurang menguasai bahan sehingga hanya mencatat materi dari buku sumber saja. Kesulitan dalam menggunakan media pembelajaran menjadi salah satu penyebab siswa kurang motivasi dalam mengikuti pembelajaran. Dari wawancara penulis dengan wakil kepala sekolah bidang kurikulum menyatakan bahwa kurangnya kesadaran guru untuk menyerahkan perencanaan pembelajaran. Ditemukan fakta tentang keadaan kepangkatan guru pada SMK Negeri 1 Padang, bahwa banyak guru yang berpangkat golongan IVa tetapi hanya sedikit sekali guru yang mencapai pangkat golongan IVb. Berikut disajikan data tentang jumlah guru menurut golongan kepangkatan di SMKN 1 Padang.

Tabel 1. Jumlah Guru SMKN 1 Padang menurut Pangkat/Golongan

\begin{tabular}{llllllll}
\hline Guru & IVc & IVb & IVa & IIId & IIIc & IIIb & IIIa \\
\hline $\begin{array}{l}\text { Adap } \\
\text { tif }\end{array}$ & - & - & 18 & 2 & 3 & 2 & - \\
$\begin{array}{l}\text { Norma } \\
\text { tif }\end{array}$ & - & - & 23 & - & 4 & 2 & 4 \\
$\begin{array}{l}\text { Pro } \\
\text { duktif }\end{array}$ & 1 & 2 & 57 & 1 & 12 & 7 & 7 \\
$\begin{array}{l}\text { Total } \\
\text { Sumber: Tata Usaha SMKN 1 Padang }\end{array}$ & 2 & 98 & 3 & 19 & 11 & 11
\end{tabular}

Dari tabel diatas terlihat bahwa setengah dari guru SMKN 1 Padang sudah berpangkat IVa yaitu $67,59 \%$ atau 98 guru tapi hanya 1,3\% saja hanya berpangkat IVb. Sedangkan guru yang perpangkat IIId yaitu hanya 2,1\% atau 3 orang guru saja berbanding lebih kecil dari guru yang memiliki pangkat IIIc yaitu 19 orang.

Kondisi ini disebabkan lemahnya kemampuan menulis karya ilmiah dan membuat penelitian di kalangan pendidik tingkat dasar dan menengah sebagai syarat untuk bisa meraih golongan yang lebih tinggi lagi. Karena pada dasarnya guru yang profesional dibangun melalui penguasaaan sejumlah kompetensi yang diperlukan untuk mendukung pelaksanaan pembelajaran.

Dari uraian diatas perlu ada dilakukan supervisi pembelajaran secara berkesinambungan terhadap kompetensi yang dimiliki guru. Khususnya agar guru mengembangkan proses pembelajaran dengan baik, melalui supervisi dari kepala sekolah. Berbagai permasalahan yang dialami guru dapat dicari jalan keluar pada akhirnya meningkatkan produktivitas kerja guru dengan baik. Hal ini dikarenakan guru yang tidak disupervisi oleh kepala sekolah tetap melaksanakan proses pembelajaran sebagaimana biasanya, kadang kadang tidak maksimal karena tugas guru merasa tidak dimonitor oleh kepala sekolah yang akhirnya produktivitas kerja guru menjadi kurang baik.

Hasil penelitian tentang kontribusi iklim kerja, motivasi kerja dan apresiasi pendidikan terhadap produktivitas kerja guru SMA PGRI di kota denpasar. Kesimpulan yang diperoleh bahwa terdapat kontribusi yang signifikan iklim organisasi, motivasi kerja dan apresiasi pendidikan secara bersama - sama terhadap produktivitas kerja guru SMA PGRI di kota Denpasar dengan kontribusi 53,3 \% [1]. Hal yang senada dengan penelitian yang dilakukan Hasil penelitian tentang hubungan pelatihan dengan produktivitas kerja guru di SMA Negeri 1 Siborong Borong. Temuan dari penelitian ini menunjukkan bahwa ada hubungan yang signifikan antara pelatihan dan produktifitas kerja guru SMA Negeri 1 Siborong-Borong [4].

\section{StUdi Pustaka}

\section{A. Produktivitas Kerja}

Secara umum makna produktivitas adalah keinginan dan upaya manusia untuk selalu meningkatkan kualitas kehidupan dan penghidupan di segala bidang. Produktivitas pendidikan berkaitan dengan bagaimana menghasilkan keluaran atau lulusan pendidikan sehingga pada akhirnya diperoleh lulusan yang berkualitas sesuai dengan kebutuhan masyarakat dan perkembangan zaman [2]. Sejauh mana pencapaian produktivitas pendidikan dapat dilihat dari output pendidikan yang dihasilkan. Pendidikan dengan berbagai programnya mempunyai peranan penting dalam meningkatkan kualitas kemampuan profesional individu atau guru dalam dunia pendidikan.

Jadi secara tidak langsung produktivitas guru akan berdampak terhadap kualitas akademis maupun moral siswa. Bila produktivitas guru tinggi maka prestasi belajar siswa akan meningkat.. . Adanya pengelolaan produktivitas kerja guru dengan baik, maka mutu pendidikan akan dapat di tingkatkan [5]. Oleh karena itu, baik atau buruk produktivitas seseorang lulusan lembaga pendidikan akan tergantung dari tingkat pemahaman materi pelajaran yang telah diserap serta pengembangannya oleh pribadi yang bersangkutan dengan lingkungan kerja.

\section{B. Kompetensi Guru}


Kompetensi merupakan suatu hal yang tidak bisa dipisahkan dari kegiatan pendidikan dan pengajaran. Hal ini disebabkan karena kompetensi guru sebagai gambaran profesional atau tidaknya tenaga pendidik (guru) dan memiliki pengaruh terhadap keberhasilan yang dicapai siswa. Dalam Peraturan Pemerintah Republik Indonesia Nomor 74 Tahun 2008 tentang Guru pada bab II Kompetensi dan Sertifikasi Pasal 3 disebutkan bahwa kompetensi merupakan seperangkat pengetahuan, keterampilan, dan perilaku yang harus dimiliki, dihayati, dikuasai, dan diaktualisasi oleh guru dalam melaksanakan tugas keprofesionalan [6].

Dari penjelasan di atas, dapat dipahami kompetensi guru merupakan kemampuan dan perilaku yang perlu dimiliki guru diharapkan dalam menjalankan tugas kependidikan optimal. Menurut Undang - Undang Republik Indonesia Nomor 14 Tahun 2005 Tentang Guru dan Dosen pada Pasal 10 disebutkan bahwa Kompetensi guru meliputi kompetensi pedagogik, kompetensi keperibadian, kompetensi sosial, dan kompetensi professional [8]. Kompetensi pedagogis berkaitan dengan kemampuan guru dalam mengelola proses pembelajaran, kompetensi kepribadian berkaitan dengan teladan bagi siswa dan masyarakat, kompetensi sosial berkaitan dengan interaksi siswa dengan guru, sedangkan kompetensi profesional merupakan kemampuan dan pengetahuan yang diperlukan guru dalam tugas pembelajaran.

\section{Persepsi Guru tentang Supervisi Pembelajaran.}

Persepsi Secara sederhana persepsi disebut sebagai pendapat yang ada pada diri seseorang. Perbedaan persepsi guru mengenai supervisi di antara sesama guru sering terjadi. Persepsi guru tentang supervisi pembelajaran dalam penelitian ini didefinisikan sebagai pemahaman guru berdasarkan penglihatan, pendengaran dan perasaannya tentang pelaksanaaan supervisi pembelajaran yang dilakukan kepala sekolah untuk meningkatkan mutu proses dan hasil pembelajaran terhadap guru. Banyak guru yang mempunyai persepsi bahwa supervisi itu identik dengan evaluasi semata - mata sehingga supervisi tidak disukai bahkan cenderung ditolak [5]. Sebaliknya cukup banyak pula guru yang mempunyai persepsi bahwa supervisi merupakan bantuan yang dapat menolong mereka mengatasi kesukaran yang mereka hadapi dalam proses pembelajaran.
Berdasarkan uraian diatas dapat disimpulkan bahwa persepsi supervisi pembelajaran oleh kepala sekolah mengacu kepada penilaian, pendapat atau pandangan guru mengenai supervisi. Bagaimana pendapat atau pandangan apabila mendengar, melihat dan mengalami dirinya disupervisi, apakah supervisi dipandang sebagai inspeksi, penilaian, atau bantuan untuk memperbaiki situasi belajar.

\section{METODE}

Jenis penelitian ini berskala ordinal dan menggunakan metode penelitian ex post facto dengan pendekatan korelasional. Populasi dalam penelitian ini adalah guru SMKN 1 Padang yang berjumlah 145 orang. Dalam penelitian ini, teknik pengambilan sampel adalah proportional random sampling sehingga diperoleh sampel 60 orang.

Variabel bebas dalam penelitian ini adalah kompetensi dan persepsi guru tentang supervisi pembelajaran sedangkan variabel dependen adalah produktivitas kerja guru. Jika dilihat dari data penelitian adalah data yang langsung diperoleh dari penyebaran angket kepada guru produktif, normatif, dan adaptif di SMKN 1 Padang. Uji coba dilakukan kepada 30 orang guru yang tidak terpilih menjadi sampel dalam penelitian yang menjadi sampel dalam penelitian. Dari hasil pengujian validitas yang diuji dengan korelasi product moment diperoleh nilai tabel korelasi 0,361 sedangkan pengujian reliabilitas diperoleh indeks reliabilitas baik pada persepsi guru terhadap supervisi pembelajaran dan juga variabel produktivitas kerja. Sedangkan data untuk variabel kompetensi guru diambil dari penilaian kepala sekolah.

Untuk teknik analisis data dilakukan deskripsi data menggunakan distribusi frekuensi dan persentasinya. Pengujian persyaratan analisis yaitu dilakukan uji normalitas dengan rumus chi kuadrat, kemudian uji linearitas yang bertujuan untuk menemukan pengaruh antar variabel, pengujian multikolinearitas yang bertujuan apakah ada tidaknya penyimpangan asumsi klasik multikolinearitas dan pengujian hipotesis yang terdiri dari analisis korelasi sederhana dan ganda, setelah itu baru dilakukan uji signifikan berserta sumbangan dari prediktor.

\section{HASIL DAN PEMBaHASAN}

\section{A. Deskripsi Data}

Data penelitian terdiri dari 3 variabel yaitu kompetensi guru yang diperoleh dari penilaian kepala sekolah terhadap kompetensi yang 
dimiliki guru, persepsi tentang supervisi pembelajaran dan produktivitas kerja guru yang diperoleh dari pengisian angket diisi oleh guru yang menjadi sampel penelitian ini sebanyak 60 orang guru.

\section{a. Kompetensi Guru}

Tabel dibawah merupakan skor kompetensi guru yang diperoleh kemudian diklasifikasikan dalam 4 kategori yang menggunakan rata -rata ideal berdasarkan kurva normal.

Tabel 2. Klasifikasi Skor Kompetensi Guru SMKN 1 Padang

\begin{tabular}{rllrc}
\hline No & Kategori & Rentang & f abs & F kum \\
\hline 1 & $\begin{array}{l}\text { Sangat } \\
\text { baik }\end{array}$ & $\geq 78$ & 43 & 71.67 \\
2 & Baik & $60 \leq$ skor $<78$ & 17 & 28.33 \\
3 & $\begin{array}{l}\text { Cukup } \\
\text { baik }\end{array}$ & $42 \leq$ skor $<60$ & - & \\
& $\begin{array}{l}\text { Kurang } \\
\text { baik }\end{array}$ & $\leq 42$ & & \\
Jumlah & & 60 & 100 \\
\hline
\end{tabular}

Berdasarkan tabel 1 diatas, dapat dilihat bahwa kompetensi guru berada kategori sangat baik 71,6\% dengan derajat pencapaian responden dengan kriteria sangat baik yaitu $84,18 \%$.

\section{b. Persepsi Guru Tentang Supervisi Pembelajaran}

Untuk memperoleh gambaran jelas tentang distribusi skor persepsi guru tentang supervisi pembelajaran dapat dilihat pada tabel 3 dibawah ini.

Tabel 3. Klasifikasi Skor Persepsi Guru Tentang Supervisi Pembelajaran SMKN 1 Padang

\begin{tabular}{rllrr}
$\begin{array}{l}\text { N } \\
\mathrm{o}\end{array}$ & Kategori & Rentang & $\begin{array}{l}\mathrm{F} \\
\text { abs }\end{array}$ & $\begin{array}{l}\text { F kum } \\
(\%)\end{array}$ \\
\hline 1 & $\begin{array}{l}\text { Sangat } \\
\text { baik }\end{array}$ & $\begin{array}{l}268.25 \\
12\end{array}$ & 20,00 \\
2 & Baik & $\begin{array}{l}52.5 \leq \text { skor }< \\
68.25\end{array}$ & 45 & 75,00 \\
& $\begin{array}{l}\text { Cukup } \\
\text { baik }\end{array}$ & $\begin{array}{l}36.75 \text { skor }< \\
52.5\end{array}$ & 3 & 5,00 \\
4 & $\begin{array}{l}\text { Kurang } \\
\text { baik }\end{array}$ & $\leq 36.75$ & & \\
& & &
\end{tabular}

Jumlah

60

100

Dari tabel terlihat kategori persepsi guru tentang supervisi pembelajaran guru berada pada kategori baik yaitu $75 \%$. Sedangkan pencapaian responden dengan kriteria interpretasi baik.

c. Persepsi Guru Tentang Produktivitas Kerja
Tabel 4 dibawah merupakan gambaran jelas tentang distribusi skor produktivitas kerja

Tabel 4. Klasifikasi Produktivitas Kerja Guru SMKN1

Padang

\begin{tabular}{rllcl}
\hline $\begin{array}{c}\text { N } \\
\mathrm{o}\end{array}$ & Kategori & Rentang & $\begin{array}{l}\text { f } \\
\text { abs }\end{array}$ & $\begin{array}{l}\mathrm{F} \\
\text { kum }\end{array}$ \\
\hline 1 & Sangat baik & $\geq 100.75$ & 17 & 28,33 \\
2 & Baik & $\begin{array}{l}77.5 \leq \text { skor }< \\
100.75\end{array}$ & 31 & 51,67 \\
3 & Cukup baik & $\begin{array}{l}74.25 \text { skkor }< \\
12\end{array}$ & 20,00 \\
& $\begin{array}{l}\text { Kurang } \\
\text { baik }\end{array}$ & $\leq 54.25$ & & \\
& & & \\
\end{tabular}

Jumlah

$60 \quad 100$

Berdasarkan tabel diatas, kategori produktivitas kerja guru berada pada kategori baik yaitu $51 \%$ dengan kriteria interpretasi baik. Kemudian peneliti juga melakukan pengujian persyaratan analisis yaitu pengujian normalitas dari setiap variabel sehingga didapatkan data berdistribusi normal. Sedangkan uji linearitas dari 2 variabel bebas tehadap variabel terikat yaitu kompetensi dan persepsi tentang supervisi pembelajaran terhadap produktivitas kerja guru SMKN 1 Padang diperoleh hasl analisis dengan persamaanregresi.

$\hat{y}=-17,0637+0,678 X_{1}+0,854 X_{2}$.

Sedangkan uji keberatian regresi diperoleh bahwa nilai $\mathrm{F}=15,535$ lebih besar dibandingkan nilai $\mathrm{F}$ tabel yaitu 3,16 sehingga menunjukkan kontribusi yang berarti dari variabel terikat terhadap variabel bebas.

Uji multikolinearitas menunjukan Hasil perhitungan diperoleh nilai tolerance masing -masing variabel sebesar 0,995 dan nilai VIF masing - masing variabel sebesar 1,005. Untuk lebih jelas dapat dilihat pada tabel 5 .

Tabel 5. Hasil uji Multikolinearitas

\begin{tabular}{cccc}
\hline & \multicolumn{3}{c}{ Statistik kolinearitas } \\
& Toleransi & \multicolumn{2}{c}{ VIF } \\
\hline $\begin{array}{c}\text { 1. Kompetensi } \\
\text { guru }\end{array}$ & &, 995 & 1,005 \\
& & \\
& & \\
& & \\
Persepsi guru & & \\
tentang & & \\
supervisi & & \\
pmbelajaran & &
\end{tabular}


a. Variabel terikat : Produktivitas kerja

Hasil diatas menunjukkan tidak ada multikolinearitas antar variabel bebas. Uji terakhir yang dilakukan adalah uji hipotesis, dari pengujian korelasi ganda didapatkan dari hasil perhitungan manual menunjukan besar interpretasi koefisien korelasi $R_{x 1 x 2 y}$ yaitu

berada dalam interval koefisien yang cukup kuat yaitu sebesar 0,616. Hal yang sama dari pengujian signifikasi Kriteria uji, tolak $H_{0}$

jika nilai hitung $\mathrm{F}$ lebih besar dari nilai tabel $\mathrm{F}$ yaitu 28,29 , dengan $d b_{1}=\mathrm{k}$, dan $d b_{2}=\mathrm{n}-\mathrm{k}$

-1 , maka $d b_{1}=2$ dan $d b_{2}=60-2-1=57$

adalah 3,16. Dengan demikian nilai hitung $\mathrm{F}$ terletak di daerah penolakan $H_{0}$ dengan

sumbangan efektif untuk variabel bebas yaitu $11 \%$ dan sumbangan relatif yaitu $34 \%$.

\section{KESIMPULAN}

Berdasarkan hasil penelitian yang telah temukan terlihat bahwa secara terpisah, baik persepsi guru tentang supervisi pembelajaran maupun kompetensi guru berkontribusi terhadap produktivitas kerja guru. Secara simultan kedua faktor tersebut memberikan kontribusi terhadap produktivitas kerja guru dengan persentase yang lebih besar. dibandingkan dengan kontribusi masing-masing secara terpisah. Hal ini menunjukan bahwa secara umum Lebih dari satu faktor yang mempengaruhi produktivitas kerja guru bersinergi. Hal ini terlihat dari hasil penelitian Tri Atmadji Sutikno (2013) ada pengaruh langsung yang signifikan antara strategi penyelesaian konflik dengan produktivitas kerja, ada pengaruh langsung yang signifikan antara motivasi kerja dengan produktivitas kerja guru [7]. Jadi dari pendapat diatas terlihat bahwa banyak faktor yang mempengaruhi produktivitas kerja guru, maka pencapaian tujuan organisasi termasuk meningkatkan produktivitas kerja guru -

akan lebih efektif. Jika organisasi sekolah dikelola dengan manajemen yang baik, termasuk manajemen supervisi pembelajaran dan bersamaan dengan itu pegawainya, khususnya guru mempersepsikan kegiatan supervisi pembelajaran kepala sekolah dengan baik dan memiliki kompetensi yang baik pula, maka akan menghasilkan produktivitas kerja yang lebih baik, daripada hanya didukung oleh salah satu faktor.

\section{DAfTAR PUStaka}

[1]. I Made Suagus Jaya. Kontribusi Iklim Kerja, Motivasi Kerja dan Apreasiasi Pendidikan Terhadap Produktivitas Kerja Guru SMA PGRI di Kota Denpasar. Tesis yang tidak diterbitkan: Universitas Pendidikan Ganesha. (2012).

[2]. Mukhtar, \& Iskandar. Orientasi Baru Supervisi Pendidikan. Jakarta: Gaung Persada. (2009).

[3]. Nurcahaya Purba. Hubungan Persepsi Guru terhadap Supervisi Pembelajaran dan Kecerdasan Emosional dengan kinerja guru SMA Negeri Kabupaten Langkat. Tesis tidak diterbitkan: Program Pascasarjana Universitas Negeri Medan. .(2006).

[4]. Sirait, Jumaria. Hubungan Pelatihan dengan Produktivitas Kerja Guru di SMA Negeri 1 SiborongBorong. 1-8 . didownloa d17 juni 2013 $d i$

http://digilib.unimed.ac.id/hubunganpelatihan-dengan-produktivitas-kerja-gurudi-sma-negeri-1-siborongborong-23902.html. (2013).

[5]. Sutarno dan salimi nurhadi. Analisis faktor faktor yang mempengaruhi organisasional Guru. Jurnal Manajemen Sumber Daya Manusia Vol 1 No 1, 63-79. (2006).

[6]. Peraturan Pemerintah Republik Indonesia nomor 74 tahun 2008 tentang Guru.

[7]. Tri Atmadji Sutikno. Studi Produktivitas Kerja Guru pada Sekolah Menengah Kejuruan Negeri di Malang Raya. Jurnal Teknologi dan Kejuruan, Vol 34, no 1 Februari 2011:1-12. (2011).

[8]. Undang - Undang Republik Indonesia Nomor 14 Tahun 2005 tentang Guru dan Dosen.

\section{Biodata Penulis}

Hamdani, lahir di Batusangkar, 6 Juni 1988. Sarjana Pendidikan dan Magister Pendidikan Teknik di Fakultas Teknik Universitas Negeri Padang. Sejak tahun 2014 menjadi staf pengajar di Jurusan Teknik Elektro FT UNP hingga sekarang. 
Krismadinata, lahir di Padang, 11 September 1977. Menyelesaiakan studi S1 di Universitas Andalas, S2 di Institut Teknologi Bandung, dan S3 di Universitas Malaya. Dosen di Jurusan Teknik Elektro Fakultas Teknik Universitas Negeri Padang sejak tahun 2000-sekarang 